\title{
Exploring the Influence of Teacher-Student Interaction Strength, Interaction Time, Interaction Distance and Interaction Content on International Student Satisfaction with Online Courses
}

\author{
Xiaozhuan Wang ${ }^{(D)}$ Aminuddin Bin Hassan* ${ }^{(D)}$, How Shwu Pyng \\ Universiti Putra Malaysia, Serdang, Malaysia \\ Han Ye \\ Zhejiang University of Science \& Technology, Hangzhou, China
}

\begin{abstract}
Since the outbreak of COVID-19 in January 2020, international online courses in universities in China have begun to develop on a large scale. This study explores the related influencing factors of teacherstudent interaction on international student satisfaction with online courses in Chinese universities. It reveals which aspects of teacherstudent interaction in online classes positively correlate with international students' satisfaction. This study is of a quantitative nature with four (independent variables (IVs) and one dependent variable (DV). The four IVs are the four dimensions of teacher-student interaction, namely interaction strength (IS), interaction time (IT), interaction content (IC), and interaction distance (ID). The DV is international student satisfaction (ISS) with online courses. This study was conducted in a university in Zhejiang Province, China. To answer the questionnaire, one hundred international students who were unable to enter China during COVID-19 were selected by stratified random sampling. The study used SPSS 21 to conduct descriptive and multiple linear regression analysis on the collected quantitative data. A total of 93 valid questionnaire data was collected. The analysis results showed that both IVs (IC \& ID) have a positive correlation with the DV (ISS). Therefore, under the condition of limited equal resources, online teachers may give priority to the teacherstudent interaction factors that have the greatest impact on the satisfaction of international students, carefully design teacher-student interaction activities, and maximise the satisfaction of international students.
\end{abstract}

Keywords: COVID-19; Teacher-Student Interaction; online courses; international student satisfaction

* Corresponding author: Aminuddin Bin Hassan, aminuddin@upm.edu.my 


\section{Introduction}

COVID-19 has persisted for more than two years since its outbreak and, as the virus continues to mutate, the epidemic may last for quite some time. The epidemic crisis has disrupted education all over the world and to ensure the continuous and stable development of teaching activities, most higher education institutions have adopted the mixed method of combining online and offline courses. As an advanced representative of education, online education is leading an all-around change in the global education field. Along with the continuous update and development of Internet technology, more and more colleges and universities have gradually turned their attention to the design and development of online courses (Esmaeeli et al., 2016). With the rapid growth of Internet technology and communication technology in the past decade, new changes have taken place in world education and, in order to adapt to these, most colleges and universities have begun to explore and develop e-learning (Babolan et al., 2016) and online education has become a part of the mainstream of higher education (Allen \& Seaman, 2006).

At present, educational internationalisation is still a relatively new educational development trend in higher education (De Wit \& Altbach, 2021); however, with the increasing trend of economic globalisation, the internationalisation of global higher education has been deepening in recent years. By 2017, the number of international students worldwide was about 5.3 million. However, the outbreak of COVID-19 has led to unique traffic control in countries worldwide in the past two years, meaning that most international students have been typically unable to enter other countries to participate in offline learning. By June 2020, 116 countries worldwide had suspended traditional offline teaching throughout the nation and had begun to conduct online education instead. The sudden epidemic has prevented overseas international students from entering China for offline learning and, as such, most Chinese universities have launched online courses for as an alternative. The most prominent feature of an online system is the separation of teachers' teaching and students' learning in time and space, which breaks the time and space constraints and can provide educational services for learners anytime, anywhere. Online learning is undoubtedly an effective means to ensure that all countries receive education during COVID-19.

However, although online courses have great potential in the development of higher education, learners sometimes are unwilling to continue learning. Student retention rates often prove to have a negative meaning in research, such as students dropping out or numbers decreasing, and higher education institutions have long focused on how they can ensure that students remain and complete their studies once they enrol (Tight, 2020). The retention rate of online courses in higher education has always been of concern by researchers (Herbert, 2006; Heyman, 2010) and some have found that the dropout rate of online classes is well above that of the traditional teaching model of face-to-face teaching (Frankola, 2001; Patterson \& McFadden, 2009).

As customers of online courses, student satisfaction is considered a critical factor in evaluating the quality of online lessons. Learning satisfaction is a subjective 
evaluation, which reflects the satisfaction of learners' needs. In the field of commercial marketing, customer satisfaction theory holds that, when customers are satisfied with a commodity, they will increase their loyalty to that commodity (Fornell et al., 1996). In addition, in the field of educational psychology, the wellknown psychologist Thorndike advanced three eminent learning laws. The law of effect shows that the higher the learners' satisfaction with learning results, the higher the possibility of continuing learning ( $\mathrm{Ni} \& \mathrm{Lu}, 2020)$. Therefore, the evaluation of student satisfaction may help researchers understand students' psychological state in the learning process, improve their learning efficiency and enhance the retention rate of courses.

Some studies have shown that student satisfaction is the crucial factor and important index affecting the quality of online education (Poortavakoli et al., 2020). Interaction can predict students' satisfaction in online courses (Ngo \& Ngadiman, 2021). However, online courses lack physical and social existence, thereby making it more difficult for teachers to interact with students. Therefore, using online interactive research to reconstruct the dialogue between teachers and students is necessary. Teacher-student interaction pays attention to students' learning motivation, learning interest, learning process (Sher, 2009), and the quality of teacher-student interaction (Aydin, 2021). Teacher-student interaction quality is related to student satisfaction (DeLoach \& Greenlaw, 2007); however, despite many studies on the interaction theme in online courses (Mehall, 2020), there seems to be no research which has explored in depth the relevant factors of teacher-student interaction affecting international student satisfaction in Chinese universities. In addition, the internationalisation of online courses in higher education is still a relatively new research field. Based on the extensive development of online courses in the world during COVID-19, this study aims to reveal which aspects of teacher-student interaction in online courses have a positive correlation with international student satisfaction, to provide an effective reference for the improvement of international student satisfaction.

\section{Literature review}

The term "online learning" includes both synchronous and asynchronous modes of teaching and learning. The COVID-19 pandemic has forced many universities around the world to rapidly transition traditional face-to-face courses to a hybrid online course model that integrates both synchronous and asynchronous (Hodges et al., 2020). Some research has confirmed that student satisfaction in the elearning process will be affected by the quality of e-Service (Pham et al., 2019). The critical factor in evaluating e-Service quality is student satisfaction (Dondi et al., 2006). Students are customers, and courses are products, thus students' learning process is a consumption process. Therefore, student satisfaction can be regarded as the entry point of creating efficient courses.

Many existing studies have paid extensive attention to student satisfaction with online courses. Zeng and Wang (2021) summarised the research on college students' learning satisfaction with online course elements designed by online teachers during COVID-19. Student satisfaction is critical in assessing online courses (Alqurashi, 2019) and the evaluation of this is closely related to the quality 
of online courses and students' performance (Kuo et al., 2014). Some previous empirical studies have also confirmed that many variable factors affect student satisfaction. Interaction is one key factor to improve the effectiveness of online teaching (Zhao et al., 2005). In the example of online courses attended by millions of university students in the US, the key driving force of students is interaction (Gleason, 2021).

Previous studies on interaction in online courses mainly focused on the influence of three different types of interaction on student satisfaction. Alqurashi (2019) showed that the overall model including all four predictive variables - selfefficacy, teacher-student interaction, student-student interaction, and studentcontent interaction - significantly impacts student satisfaction. Gavrilis et al. (2020) conducted a quantitative survey of 115 graduate students in the Open University of Greece on their satisfaction with online courses. The results showed that the level of interaction distance between teachers and students was low and the distance between students and students and between students and content transactions was high. In addition, overall, the 115 graduate students seemed to be satisfied with the interactive distance of online courses

From the perspective of teachers' perception of the importance of online curriculum interaction, teacher-student interaction is the key factor affecting online courses (Su et al., 2005). Thurmond (2003) identified that teacher-student interaction is the biggest key predictor of student satisfaction and Northrup (2001) believed that it plays an important role in improving student satisfaction with online courses in distance education. Teacher-student interaction is a significant predictor of online student satisfaction (Marks et al., 2005). Compared with student-student interaction, students believe that teacher-student interaction is more important to their learning (Kyei-Blankson et al., 2019): teacher-student interaction positively impacts online student satisfaction (Kuo et al., 2014). Lin et al. (2017) conducted regression analysis on quantitative data through empirical research, and their conclusion was the same as that of Kuo et al. (2014). Yukselturk and Yildirim (2008) confirmed that teacher-student interaction is one of the most important predictors of online student satisfaction, while Martyn (2005) pointed out that it is necessary to purposefully create an environment that supports cooperation between teachers and students. This deliberately planned environment is conducive to students' success in an online environment. In online courses, teachers are facilitators of classes, not leaders. Further, interaction is a crucial factor in ensuring student satisfaction and retention (Bray et al., 2008).

To save the cost of distance education, Anderson (2002) proposed a theory of interaction design: equivalent interaction theory. The core content of this theory is that the three types of interaction in distance learning (learner and content, learner and teacher, learner and learner) can be replaced by each other. In other words, if one of the three types of interaction in distance learning remains at a high level, it can promote the learning of online learners to a great extent. The contribution of this theory to this study is that we can design effective teacherstudent interaction to promote students' online learning and improve student satisfaction. 
Xu's (2016) research shows that the quality of interaction content will affect online learning performance. Interaction strength refers to the amount of information generated between teachers and students per unit time in the interaction process. It is generally believed that the greater the amount of data generated between teachers and students, the higher the intensity of synchronous interaction. Interaction time is closely related to interaction frequency and interaction quantity. Swan (2002) analysed the data of 73 online courses and found that the frequency of teacher-student interaction positively impacted student satisfaction in online courses. Eom et al. (2006) used a structural equation model to explore the factors affecting online student satisfaction, with the results showing that the number of interactions has a significant positive impact on online student satisfaction. Some studies have also pointed out that the smaller the interaction distance between teachers and students, the easier it is to produce effective learning (Xiao \& Huang, 2014). Teacher-student interaction strength, interaction content prepared by teachers, and the length of interaction time are the incentive factors in the online learning environment, which can be said to be the antecedent variables. Interaction distance refers to the change of students' perceived psychological distance from teachers under the influence of the external environment. This view may affect students' satisfaction. Therefore, this study believes that in the process of teacher-student interaction in online courses, the interaction content (IC), interaction strength (IS), interaction time (IT), and interaction distance (ID) may be related to international student satisfaction (ISS).

In the past ten years, e-learning has gradually developed into an indispensable part of higher education. However, despite extensive relevant research in this field, many educators are still concerned about how to use online learning effectively (Tratnik et al., 2019). Through the review of previous relevant studies, this study found that teacher-student interaction is the key factor affecting student satisfaction in online courses. However, there are still gaps in research on which aspects of teacher-student interaction are related to international student satisfaction with online courses.

\subsection{Research Questions}

In this context, the research questions are:

1) Does the content of teacher-student interaction in online courses correlate with international student satisfaction?

2) Does the strength of teacher-student interaction in online courses correlate with international student satisfaction?

3) Does the time of teacher-student interaction in online courses correlate with international student satisfaction?

4) Does the distance of teacher-student interaction in online courses correlate with international student satisfaction? 


\section{Methodology}

\subsection{Study Design}

This study uses quantitative research methods to establish four aspects of teacherstudent interaction as IVs and international student satisfaction with the online course as a DV. Quantitative data were collected through questionnaires collected by online teachers. SPSS software was used for data analysis to provide descriptive analysis on the variables of quantitative data and multiple regression analysis on the relationship between IVs and DV.

\subsection{Participants}

Using stratified sampling, 100 international students who have been receiving online courses since March 2020 were selected as the research sample in a university in Zhejiang Province, China. Generally, in China's science and technology universities, the proportion of male students greatly outweighs the proportion of female students. In addition, the proportion of science and engineering majors in Chinese Universities of science and technology will also be higher than that of liberal arts majors. As shown in Table 1, the proportion of male and female students and the proportion of majors are reflected in the sample.

Table 1: Demographic Information

\begin{tabular}{lcc}
\hline Demographic Information & $\mathrm{v}$ & $\%$ \\
\hline Gender & 63 & $63 \%$ \\
Male & 37 & $37 \%$ \\
Female & & \\
Major & 66 & $66 \%$ \\
Science \& Engineering & 34 & $34 \%$ \\
Literature \& History & & \\
\hline
\end{tabular}

\subsection{Questionnaire Design}

The questionnaire has a total of 15 measurement items and five latent variables, which are, respectively, three dimensions of the teacher-student online interaction process (IS, IT \& IC), one dimension of teacher-student online interaction results (ID), and one dimension of ISS.

Most of the measurement items in Table 2 come from mature questionnaires. The measurement items of IC refer to Xu's (2016) research results on teacher-student interaction and e-learning performance. The measurement item setting of IS refers to individual difference research on teacher-student interaction (Xu et al., 2016). The measurement item settings of ID are from the research investigating factors affecting the social presence and user satisfaction with mobile instant messaging (Ogara et al., 2014). The measurement items of ISS refer to Wu and Liu (2013).

The scale is tested with a Likert five-level scale. From low to high levels, they are: Strongly disagree, Disagree, Neutral, Agree, and Strongly agree. They are assigned 1-5 respectively and scored in turn; the higher the score, the better the 
experience of online learners in the dimension. The measurement items of each dimension are shown in Table 2.

Table 2: Questionnaire Information

\begin{tabular}{|c|c|}
\hline Latent variable & Measurement item \\
\hline Interaction Strength & $\begin{array}{l}\text { 1. The teacher can answer my questions immediately. } \\
\text { 2. After submitting homework online, the teacher can give } \\
\text { feedback immediately. }\end{array}$ \\
\hline \multirow[t]{2}{*}{ Interaction Time } & $\begin{array}{l}\text { 3. The teacher often asks questions in an online class. } \\
\text { 4. After class, the teacher often answers our concerns on the } \\
\text { Internet. } \\
\text { 5. Teachers often participate in class discussion activities. }\end{array}$ \\
\hline & $\begin{array}{l}\text { 6. Teachers often provide feedback about classroom homework } \\
\text { before the second class. }\end{array}$ \\
\hline Interaction Content & $\begin{array}{l}\text { 7. The questions set by teachers are closely related to classroom } \\
\text { knowledge. } \\
8 \text {. The teacher will summarise the knowledge points and set } \\
\text { relevant exercises in each class. } \\
\text { 9. The questions raised by the teacher are instructive. }\end{array}$ \\
\hline Interaction Distance & $\begin{array}{l}\text { 10. In online courses, I can feel the presence of teachers when I } \\
\text { communicate with them. } \\
\text { 11. In the online course, when I communicate with the teacher, } \\
\text { I feel the same as face-to-face communication. } \\
\text { 12. I don't feel nervous when communicating with teachers in } \\
\text { the online course. }\end{array}$ \\
\hline \multirow[t]{2}{*}{$\begin{array}{l}\text { International Students' } \\
\text { Satisfaction }\end{array}$} & $\begin{array}{l}\text { 14. Generally speaking, online courses can meet my learning } \\
\text { needs. }\end{array}$ \\
\hline & $\begin{array}{l}\text { 15. I am willing to accept the online teaching mode in the } \\
\text { future. }\end{array}$ \\
\hline
\end{tabular}

\subsection{Test of Questionnaire and Sample Selection}

Before the formal use of the questionnaire, this study was distributed in a small range. The participants were international students majoring in online business Chinese in a university in Zhejiang Province, China. A total of 30 online questionnaires was distributed, two of which were deleted because they were incomplete. During the questionnaire trial, the participants did not express their opinions on the measurement items.

After the pilot study, this study distributed the questionnaire to international students in the same university. The missing value was processed by deleting the record as long as there was missing. In this study, as many as 100 questionnaires were recovered. After excluding seven invalid questionnaires, 93 questionnaires remained, with an effective rate of $93 \%$.

\subsection{Reliability and Validity of the Questionnaire}

Reliability refers to the internal consistency of the survey results. Generally speaking, the higher the reliability value, the more reliable the measurement 
result. In this study, Cronbach's alpha was used to analyse the reliability of the questionnaire. The analysis results are shown in Table 3.

Table 3: Reliability of questionnaire

\begin{tabular}{cccccc}
\hline Latent Variable & IS & IT & IC & ID & ISS \\
\hline Cronbach's alpha & .745 & .876 & .768 & .821 & .853 \\
\hline
\end{tabular}

As shown in Table 3, the Cronbach's alpha values of the interaction strength dimension, interaction time dimension, interaction content dimension, and interaction distance dimension are all above 0.7, at the "good" level. The Cronbach's alpha of the ISS is more significant than 0.8 (Hair, 2011), indicating that the reliability of the ISS is "ideal". In conclusion, this questionnaire has higher reliability.

This study mainly uses construct validity to illustrate the validity of this questionnaire. The criterion-related validity of the questionnaire is shown in Table 4. The factor loading of all measurement items in the questionnaire is more significant than 0.6, AVE (mean-variance extraction value) is higher than 0.5 , and $\mathrm{CR}$ is more than 0.7. The questionnaire of this study meets the three index requirements of criterion-related validity simultaneously, so it can be considered that the measurement model has good criterion-related validity.

Table 4: Validity of the questionnaire

\begin{tabular}{|c|c|c|c|c|}
\hline Latent Variable & Observed Variable & Factor loading & CR & AVE \\
\hline \multirow{2}{*}{$\begin{array}{c}\text { Interaction } \\
\text { Strength }\end{array}$} & IS1 & .80 & \multirow[t]{2}{*}{.754} & \multirow[t]{2}{*}{.601} \\
\hline & IS2 & .75 & & \\
\hline \multirow{4}{*}{$\begin{array}{l}\text { Interaction } \\
\text { Time }\end{array}$} & IT1 & .78 & \multirow[t]{4}{*}{.876} & \multirow[t]{4}{*}{.646} \\
\hline & IT2 & .80 & & \\
\hline & IT3 & .87 & & \\
\hline & IT4 & .76 & & \\
\hline \multirow{3}{*}{$\begin{array}{c}\text { Interaction } \\
\text { Content }\end{array}$} & IC1 & .65 & \multirow[t]{3}{*}{.768} & \multirow[t]{3}{*}{.531} \\
\hline & IC2 & .78 & & \\
\hline & IC3 & .75 & & \\
\hline \multirow{3}{*}{$\begin{array}{l}\text { Interaction } \\
\text { Distance }\end{array}$} & ID1 & .62 & \multirow[t]{3}{*}{.821} & \multirow[t]{3}{*}{.633} \\
\hline & ID2 & .87 & & \\
\hline & ID3 & .87 & & \\
\hline \multirow{3}{*}{$\begin{array}{l}\text { International } \\
\text { Students' } \\
\text { Satisfaction }\end{array}$} & ISS1 & .77 & \multirow[t]{3}{*}{.853} & \multirow[t]{3}{*}{.677} \\
\hline & ISS2 & .84 & & \\
\hline & ISS3 & .85 & & \\
\hline
\end{tabular}

\subsection{Statistical Analysis}

To answer whether four IVs are related to DV, this study used SPSS data software to analyse the collected data.

\subsection{Descriptive Statistics Analysis}

This study makes a descriptive statistical analysis of the four dimensions (IS, IT, IC, and ID) of teacher-student interaction and ISS to understand the data 
characteristics. A score of 3 indicates that the international student's attitude towards the item is "Neutral", a score of 4 indicates that the international student's attitude towards the item is "Satisfaction". A score of 5 indicates that the international student's attitude towards the item is "High satisfaction".

\subsection{Regression Analysis}

This study takes interaction strength (IS), interaction time (IT), interaction content (IC), and interaction distance (ID) as the independent variables (IVs) and international student satisfaction (ISS) as the dependent variable (DV), selects stepwise method, carries out regression analysis on the collected data and reveals the causal relationship between IVs and DV in online courses.

\section{Results}

\subsection{The Results of Descriptive Statistics Analysis}

The data description results are shown in Table 5. The mean values of IC, IS, IT, and ID, and ISS are more than 4 points and less than 4.5 points. International students' attitudes are between "Satisfaction" and "High satisfaction", higher than the average value of the 5-point system and close to the maximum 5-point test, indicating that international students are delighted with the teacher-student interaction of online courses.

Table 5: Descriptive analysis of variables

\begin{tabular}{|c|c|c|c|}
\hline Latent Variable & Item & Item Mean & Variable Mean \\
\hline Interaction & IS1 & 4.30 & \\
\hline Strength & IS2 & 4.33 & 4.32 \\
\hline \multirow{4}{*}{$\begin{array}{c}\text { Interaction } \\
\text { Time }\end{array}$} & IT1 & 4.37 & \multirow{4}{*}{4.41} \\
\hline & IT2 & 4.31 & \\
\hline & IT3 & 4.45 & \\
\hline & IT4 & 4.52 & \\
\hline \multirow{3}{*}{$\begin{array}{c}\text { Interaction } \\
\text { Content }\end{array}$} & IC1 & 4.34 & \multirow{3}{*}{4.19} \\
\hline & IC2 & 4.12 & \\
\hline & IC3 & 4.12 & \\
\hline \multirow{3}{*}{$\begin{array}{c}\text { Interaction } \\
\text { Distance }\end{array}$} & ID1 & 4.32 & \multirow{3}{*}{4.28} \\
\hline & ID2 & 4.30 & \\
\hline & ID3 & 4.28 & \\
\hline International & ISS1 & 4.23 & \multirow{3}{*}{4.20} \\
\hline Students' & ISS2 & 4.20 & \\
\hline Satisfaction & ISS3 & 4.17 & \\
\hline
\end{tabular}

The mean value of interaction strength is 4.32 , and the scores of each item are similar, indicating that teachers should provide timely feedback on learners' online problems and homework. The dimension of interaction time includes four items, and the mean value is the highest in the measurements. It shows that online teachers spend more time interacting with international students and maintaining close communication with them. The mean value of both IT3 and IT4 is higher, indicating that teachers spend more time participating in online discussion and homework feedback than classroom questions and answers. 
Among the four dimensions of teacher-student interaction, the mean value of interaction content is the lowest, and the scores of IC2 and IC3 items are the weakest among all items, indicating that the design of interaction content of online courses needs to be improved, especially the inspiration and novelty of problems. The mean value of the interaction distance dimension is 4.28 , and the mean values of the three items are close, indicating that, in the process of online learning, the psychological distance between teachers and students is small, and learners can easily feel the existence of teachers. The dimension of the ISS is 4.20. The mean values of the three measurement indicators of ISS are all greater than 4 points, and the scores are relatively close, which indicates that online courses generally meet the learning needs of international students, and students are more willing to continue to choose online courses.

\subsection{The Results of Regression Analysis}

As shown in Table 6, Adjusted R Square is .647. With the increase of independent variables, Adjusted R Square also increases, indicating that, with the adjustment of the regression model, the explanatory variables become larger and larger. In addition, the Durbin-Watson value is 2.148. Therefore, it can be considered that the residuals and IVs are independent of each other, and the research results obtained by regression analysis have high reliability.

Table 6: Model summary

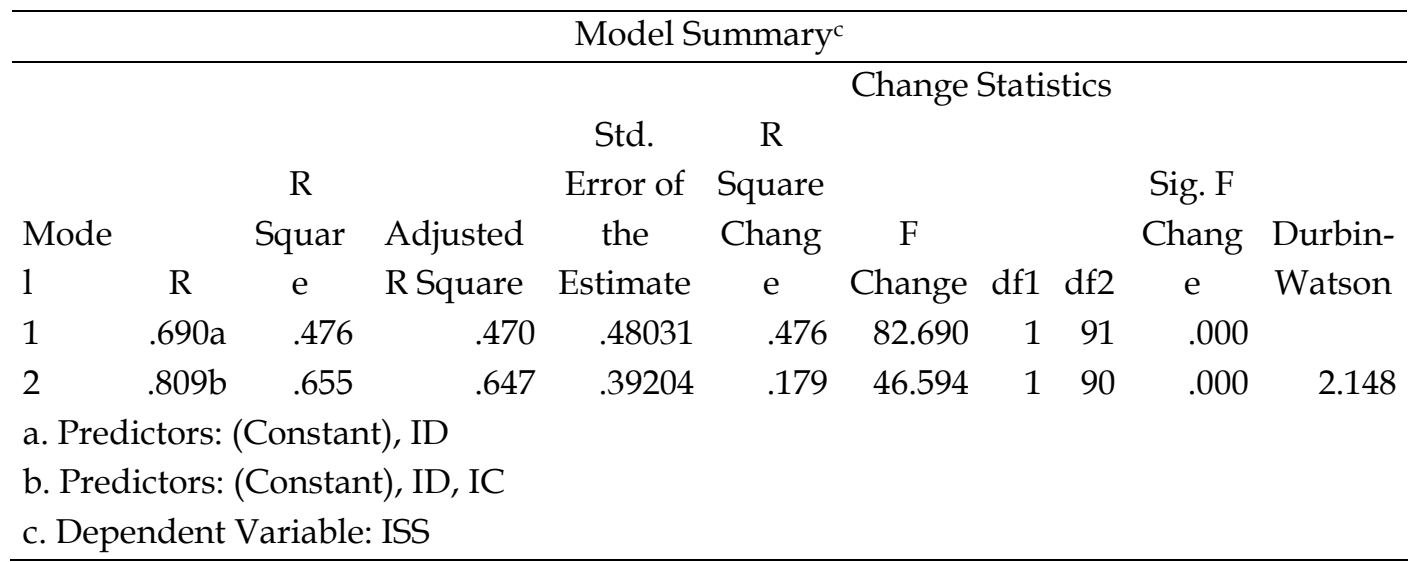

It can be seen from Table 7 that the first independent variable entering the regression equation is the interaction distance, followed by the interaction content. The Sig. F values of the two models are. $000(<.05)$, which shows that there is an apparent regression relationship between the two IVs (i.e., ID, IC) and DV (ISS).

Table 7: ANOVA

\begin{tabular}{|c|c|c|c|c|c|c|}
\hline \multicolumn{7}{|c|}{ ANOVA $^{a}$} \\
\hline Model & & $\begin{array}{l}\text { Sum of } \\
\text { Squares }\end{array}$ & $\mathrm{df}$ & Mean Square & $\mathrm{F}$ & Sig. \\
\hline \multirow[t]{3}{*}{1} & Regression & 19.076 & 1 & 19.076 & 82.690 & $.000^{\mathrm{b}}$ \\
\hline & Residual & 20.994 & 91 & 231 & & \\
\hline & Total & 40.070 & 92 & & & \\
\hline
\end{tabular}




\begin{tabular}{|c|c|c|c|c|c|c|}
\hline \multicolumn{7}{|c|}{ ANOVA $^{a}$} \\
\hline Model & & $\begin{array}{l}\text { Sum of } \\
\text { Squares }\end{array}$ & $\mathrm{df}$ & Mean Square & $\mathrm{F}$ & Sig. \\
\hline \multirow[t]{3}{*}{2} & Regression & 26.238 & 2 & 13.119 & 85.357 & .000 \\
\hline & Residual & 13.832 & 90 & 154 & & \\
\hline & Total & 40.070 & 92 & & & \\
\hline \multicolumn{7}{|c|}{ a. Dependent Variable: ISS } \\
\hline \multicolumn{7}{|c|}{ b. Predictors: (Constant), ID } \\
\hline \multicolumn{7}{|c|}{ c. Predictors: (Constant), ID, IC } \\
\hline
\end{tabular}

As shown in Table 8, the tolerance values are more significant than 0.1 (close to 1) and VIF $<10$. So, it can be considered that no collinearity problem exists among the variables. In addition, the Sig. of IVs $=.000(<.05)$, which indicates that the two independent variables are statistically significant in the model and should be retained. It can be seen that the interaction distance and interaction content have a significant impact on international student satisfaction with the online course and has a certain influence, and the influence coefficients are 0.628 and 0.428 .

Table 8: Coefficients

\begin{tabular}{|c|c|c|c|c|c|c|c|}
\hline \multicolumn{8}{|c|}{ Coefficients $^{\mathrm{a}}$} \\
\hline & \multicolumn{2}{|c|}{$\begin{array}{c}\text { Unstandardised } \\
\text { Coefficients }\end{array}$} & \multicolumn{2}{|l|}{$\begin{array}{c}\text { Standardised } \\
\text { Coefficients }\end{array}$} & & \multicolumn{2}{|c|}{$\begin{array}{l}\text { Collinearity } \\
\text { Statistics }\end{array}$} \\
\hline & & Std. & & & & & \\
\hline Model & B & Error & Beta & $\mathrm{t}$ & Sig. & Tolerance & VIF \\
\hline 1 (Constant) & 1.004 & .355 & & 2.829 & .048 & & \\
\hline ID & .743 & .082 & .690 & 9.093 & .000 & 1.000 & 1.000 \\
\hline 2 (Constant) & 2.489 & .859 & & 2.897 & .000 & & \\
\hline ID & .628 & .069 & .584 & 9.141 & .000 & .941 & 1.063 \\
\hline IC & .420 & .061 & .436 & 6.826 & .000 & .941 & 1.063 \\
\hline
\end{tabular}

\section{Discussion}

The results of descriptive statistical analysis showed that international students were satisfied with teacher-student interaction strength, interaction content, interaction time, and interaction distance in online courses conducted during the COVID-19 period. It is a positive finding that online courses overall meet the learning needs of international students, and students are willing to continue to choose online courses. This shows that online courses have great potential in adapting to new changes in global education (Babolan et al., 2016).

The results of multiple linear regression analysis show that teacher-student interaction content in online courses has a positive impact on the satisfaction of international students. This research result is consistent with Xu's (2016) research, indicating that the quality of interaction content will affect the performance and satisfaction of online learning. The interaction distance in online courses is positively correlated with the satisfaction of international students, which indicates that, when students feel the presence or attention of online teachers, it 
will effectively reduce the loneliness of students in the online environment, which will lead to a good experience and learning effects (Xiao \& Huang, 2014). In this study, teacher-student interaction strength and interaction time did not have a direct positive effect on international student satisfaction, which was slightly similar to the results of Swan (2002) to some extent. The inconsistency may be due to the overall intensity and length of online courses during the COVID-19 period.

\section{Conclusions}

The purpose of this study is to reveal which aspects of teacher-student interaction in online courses have a positive correlation with international student satisfaction. The first research question is whether teacher-student interaction content is correlated with international students' satisfaction with online courses. The analysis of the research results shows that interaction content has a positive impact on international students' satisfaction in online courses. The second research question is whether interaction strength is related to international students' satisfaction with online courses. The result shows that there is no direct correlation between interaction strength and international students' satisfaction with online courses. The third research question is whether interaction time is associated with international students' satisfaction with online courses. The result shows that there is no direct correlation between interaction time and international students' satisfaction with online courses. The fourth research question is whether interaction distance is related to international student satisfaction with online courses. The result shows that interaction distance has a positive impact on international students' satisfaction in online courses. To sum up, the results of this study show that teacher-student interaction content and interaction distance are the key factors affecting international students' satisfaction with online courses, which provides a new way to improve the satisfaction of international students. This study has certain limitations: it was conducted during a period of high-intensity online courses during the epidemic, and the results may be different from those of the non-epidemic period.

\subsection{Contributions and Implications}

This study shows that carefully designing the interaction content of online courses and shortening the interaction distance can effectively improve the satisfaction of international students' online courses. This research is innovative both due to the research objectives- as it is conducted among international students, and the whole online course practice, which has never been done before. This study provides an empirical analysis reference for the development of international online courses in Chinese colleges and universities and reveals teacher-student interaction content and distance in online courses have a positive correlation with international students' satisfaction. Future research should further explore the effects of interaction motivation, interaction tools, learners' language level, and gender as regulatory variables on learners' satisfaction.

\section{References}

Allen, I. E., \& Seaman, J. (2006). Growing by degrees: Online education in the United States, 2005. Sloan Consortium (NJ1). 
Alqurashi, E. (2019). Predicting student satisfaction and perceived learning within online learning environments. Distance Education, 40(1), 133-148. https://doi.org/10.1080/01587919.2018.1553562

Anderson, T. (2002, May). An updated and theoretical rationale for interaction. In Athabasca University: IT Forum Paper (Vol. 63).

Aydin, B. (2021). Determining the effect of student-content interaction, instructor-student interaction and student-student interaction on online education satisfaction level. University of South Florida M3 Center Publishing, 3(2021), 16.

Babolan, A. Z., Kia, M. M., \& Derakhshanffard, S. (2016). The Role of eLearning in Higher Education System and its Challenges. In the First International Conference on Modern Research in the Field of Education Sciences and Psychology and Social Studies of Iran, Qom, International Institute for the Study of Middle East Science.

Bray, E., Aoki, K., \& Dlugosh, L. (2008). Predictors of learning satisfaction in Japanese online distance learners. International Review of Research in Open and Distributed Learning, 9(3), 1-24. https:/ / doi.org/10.19173/irrodl.v9i3.525

De Wit, H., \& Altbach, P. G. (2021). Internationalization in higher education: global trends and recommendations for its future. Policy Reviews in Higher Education, 5(1), 28-46. https://doi.org/10.1080/23322969.2020.1820898

DeLoach, S. B., \& Greenlaw, S. A. (2007). Effectively moderating electronic discussions. The Journal of Economic Education, 38(4), 419-434. https://doi.org/10.3200/JECE.38.4.419-434

Dondi, C., Moretti, M., \& Nascimbeni, F. (2006). Quality of e-learning: Negotiating a strategy, implementing a policy. In Handbook on quality and standardization in elearning (pp. 31-50). Springer, Berlin, Heidelberg.

Eom, S. B., Wen, H. J., \& Ashill, N. (2006). The determinants of students' perceived learning outcomes and satisfaction in online university education: An empirical investigation. Decision Sciences Journal of Innovative Education, 4(2), 215-235. https:/ / doi.org/10.1111/j.1540-4609.2006.00114.x

Esmaeeli, H., Rahmani, S., Kazemi, A., \& Ali Ahmadi, M. (2016). Evaluation of E-Learning of the virtual learning program from the student's point of view. Public Management Research, 9(34), 203-222.

Fornell, C., Johnson, M. D., Anderson, E. W., Cha, J., \& Bryant, B. E. (1996). The American customer satisfaction index: nature, purpose, and findings. Journal of Marketing, 60(4), 7-18.

Frankola, K. (2001, Jun 3). Why online learners drop out. https://workforce.com/news/why-online-learners-drop-out.

Gavrilis, V., Mavroidis, I., \& Giossos, Y. (2020). Transactional distance and student satisfaction in a postgraduate distance learning program. Turkish Online Journal of Distance Education, 21(3), 48-62. https:/ / doi.org/10.17718/tojde.762023

Gleason, B. (2021). Expanding interaction in online courses: integrating critical humanizing pedagogy for learner success. Educational Technology Research and Development, 69(1), 51-54. https:/ / doi.org/10.1007/s11423-020-09888-w

Hair, J. F., Ringle, C. M., \& Sarstedt, M. (2011). PLS-SEM: Indeed a silver bullet. Journal of Marketing theory and Practice, 19(2), 139-152. https://doi.org/10.2753/MTP10696679190202

Herbert, M. (2006). Staying the course: A study in online student satisfaction and retention. Online Journal of Distance Learning Administration, 9(4), 300-317.

Heyman, E. (2010). Overcoming student retention issues in higher education online programs. Online Journal of Distance Learning Administration, 13(4).

Hodges, C. B., Moore, S., Lockee, B. B., Trust, T., \& Bond, M. A. (2020). The difference between emergency remote teaching and online learning. 
Kuo, Y. C., Walker, A. E., Schroder, K. E., \& Belland, B. R. (2014). Interaction, Internet selfefficacy, and self-regulated learning as predictors of student satisfaction in online education courses. The Internet and higher education, 20, 35-50. https://doi.org/10.1016/j.iheduc.2013.10.001

Kyei-Blankson, L., Ntuli, E., \& Donnelly, H. (2019). Establishing the importance of interaction and presence to student learning in online environments. Journal of Interactive Learning Research, 30(4), 539-560.

Lin, C. H., Zheng, B., \& Zhang, Y. (2017). Interactions and learning outcomes in online language courses. British Journal of Educational Technology, 48(3), 730-748. https://doi.org/10.1111/bjet.12457

Marks, R. B., Sibley, S. D., \& Arbaugh, J. B. (2005). A structural equation model of predictors for effective online learning. Journal of management education, 29(4), 531563. https://doi.org/10.1177/1052562904271199

Martyn, M. A. (2005). Using interaction in online discussion boards. Educause Quarterly, 28(4), 61.

McFadden, C., \& Patterson, B. (2009). Attrition in online and campus degree programs. Online Journal of Distance Learning Administration, 7(2).

Mehall, S. (2020). Purposeful Interpersonal Interaction in Online Learning: What Is It and How Is It Measured?. Online Learning, 24(1), 182-204.

Ngo, J., \& Ngadiman, A. (2021). Investigating Student Satisfaction in Remote Online Learning Settings During Covid-19 in Indonesia. Journal of International and Comparative Education (JICE), 73-95. https://doi.org/10.14425/jice.2021.10.2.0704

Ni, Y., \& Lu, J. (2020). Research on Junior High School English Reading Class Based on the Principle of Timing and Thorndike's Three Laws of Learning. Journal of Language Teaching and Research, 11(6), 962-969.

Northrup, P. (2001). A framework for designing interactivity into web-based instruction. Educational technology, 41(2), 31-39.

Ogara, S. O., Koh, C. E., \& Prybutok, V. R. (2014). Investigating factors affecting the social presence and user satisfaction with mobile instant messaging. Computers in Human Behavior, 36, 453-459. https:// doi.org/10.1016/j.chb.2014.03.064

Pham, L., Limbu, Y. B., Bui, T. K., Nguyen, H. T., \& Pham, H. T. (2019). Do e-learning service quality influence e-learning student satisfaction and loyalty? Evidence from Vietnam. International Journal of Educational Technology in Higher Education, 16(1), 1-26.

Poortavakoli, A., Alinejad, M., \& Daneshmand, B. (2020). Designing a pattern for e-content development based on the factors affecting satisfaction in e-learning. The technology of Education Journal (TEJ), 15(1), 119-138. https:// doi.org/10.22061/TEJ.2020.4490.2074

Sher, A. (2009). Assessing the relationship of student-instructor and student-student interaction to student learning and satisfaction in web-based online learning environment. Journal of Interactive Online Learning, 8(2).

Su, B., Bonk, C. J., Magjuka, R. J., Liu, X., \& Lee, S. H. (2005). The importance of interaction in web-based education: A program-level case study of online MBA courses. Journal of Interactive Online Learning, 4(1), 1-19.

Swan, K. (2002). Building learning communities in online courses: The importance of interaction. Education, Communication \& Information, 2(1), 23-49.

Thurmond, V. A. (2003). Examination of interaction variables as predictors of students satisfaction and willingness to enroll in future Web-based courses while controlling for student characteristics. In Society for Information Technology \& Teacher Education International Conference (pp. 528-531). Association for the Advancement of Computing in Education (AACE). 
Tight, M. (2020). Student retention and engagement in higher education. Journal of further and Higher Education, 44(5), 689-704. https://doi.org/10.1080/0309877X.2019.1576860

Tratnik, A., Urh, M., \& Jereb, E. (2019). Student satisfaction with an online and a face-toface Business English course in a higher education context. Innovations in Education and Teaching International, 56(1), 36-45. https:// doi.org/10.1080/14703297.2017.1374875

Wang, Y. S. (2003). Assessment of learner satisfaction with asynchronous electronic learning systems. Information $\mathcal{E} \quad$ Management, 41(1), 75-86. https:// doi.org/10.1016/S0378-7206(03)00028-4

Wu, J., \& Liu, W. (2013). An empirical investigation of the critical factors affecting students satisfaction in EFL blended learning. Journal of Language Teaching \& Research, 4(1)

Xiao, G. D., \& Huang, R. H. (2014). Xuexi Guocheng Daoxiang de Wangluo Kecheng Jiaoxue Jiaohu Sheji Yanjiu - Mianxiang Wangluo Kecheng Shishi de Shijiao [Study on teaching interaction design of learning process-oriented online courses - A perspective for online course implementation.] Research in Electro-Chemical Education, 35(9), 85-90.

Xu, E. Q. (2016). Shisheng Jiaohu Yingxiang Wangluo Xuexi Jixiao de Shizheng Fenxi [An empirical analysis of teacher-student interaction affecting online learning performance.] Research in e-learning, 37(9), 61-68.

Xu, E., Xu, L. R., \& Cui, G. Z. (2016). Shisheng Jiaohu de Geti Chayi Yanjiu - Jiyu Fanzhuan Ketang de Gean Diaocha Fenxi [A study of individual differences in teacherstudent interaction: A case study and analysis based on flipped classroom.] Chinese e-learning, (8), 67-73.

Yukselturk, E., \& Yildirim, Z. (2008). Investigation of interaction, online support, course structure, and flexibility contribute to students' satisfaction in an online certificate program. Journal of Educational Technology \& Society, 11(4), 51-65.

Zeng, X., \& Wang, T. (2021). College Student Satisfaction with Online Learning during COVID-19: A review and implications. International Journal of Multidisciplinary Perspectives in Higher Education, 6(1), 182-195.

Zhao, Y., Lei, J., Yan, B., Lai, C., \& Tan, S. (2005). What makes the difference? A practical analysis of research on the effectiveness of distance education. Teachers College Record, 107(8), 1836-1884. 


\begin{abstract}
APPENDIX
Dear Student:

Hello! At present, I am doing research on how to effectively use Teacher-Student Interaction to improve the satisfaction of online learners. I need to know your learning needs and opinions of online courses during the epidemic, which is of great significance to you and this research. Therefore, please truthfully fill in each option in the questionnaire according to your actual learning situation and real ideas. This volume is anonymous. All information you fill in is limited to this study and will not be used for other purposes. Thank you very much for your support and cooperation!
\end{abstract}

\title{
Part 1: Demographics
}

\section{1-2:}

Please enter the following demographic information:

1. Your gender:
A.male
B.female

2. Your major:
A. Science and Engineering
B. Linguistics C.Literature and history
D. A\&D E.Other

Part 2: This part was measured by a Likert 5-point scale. Please read and respond to each question or statement carefully and select the answer that most reflects your expectations, opinions, or beliefs.

1.The teacher can answer my questions immediately.

1. Strongly Agree 2. Agree 3. Neutral 4. Disagree 5. Strongly Disagree

2. After submitting homework online, the teacher can give feedback immediately.

\section{Strongly Agree 2. Agree 3. Neutral 4. Disagree 5. Strongly Disagree}

3. The teacher often asks questions in an online class.

1. Strongly Agree 2. Agree 3. Neutral 4. Disagree 5. Strongly Disagree

4. After class, the teacher often answers our concerns on the Internet.

1. Strongly Agree 2. Agree 3. Neutral 4. Disagree 5. Strongly Disagree

5. Teachers often participate in class discussion activities.

1. Strongly Agree 2. Agree 3. Neutral 4. Disagree 5. Strongly Disagree 
6. Teachers often provide feedback about classroom homework before the second class.

1. Strongly Agree 2. Agree 3. Neutral 4. Disagree 5. Strongly Disagree

7. The questions set by teachers are closely related to classroom knowledge.

1. Strongly Agree 2. Agree 3. Neutral 4. Disagree 5. Strongly Disagree

8. The teacher will summarize the knowledge points and set relevant exercises in each class.

1. Strongly Agree 2. Agree 3. Neutral 4. Disagree 5. Strongly Disagree

9. The questions raised by the teacher are instructive.

1. Strongly Agree 2. Agree 3. Neutral 4. Disagree 5. Strongly Disagree

10. In online courses, I can feel the presence of teachers when I communicate with them.

1. Strongly Agree 2. Agree 3. Neutral 4. Disagree 5. Strongly Disagree

11. In the online course, when I communicate with the teacher, I feel the same as face-to-face communication.

1. Strongly Agree 2. Agree 3. Neutral 4. Disagree 5. Strongly Disagree

12. I don't feel nervous when communicating with teachers in the online course.

1. Strongly Agree 2. Agree 3. Neutral 4. Disagree 5. Strongly Disagree

13. Generally speaking, I prefer online learning.

1. Strongly Agree 2. Agree 3. Neutral 4. Disagree 5. Strongly Disagree

14. Generally speaking, online courses can meet my learning needs.

1. Strongly Agree 2. Agree 3. Neutral 4. Disagree 5. Strongly Disagree

15. I am willing to accept the online teaching mode in the future.

1. Strongly Agree 2. Agree 3. Neutral 4. Disagree 5. Strongly Disagree 